\title{
Emerging Legal Issues in Sub-Orbital Flight and Colonization under International Air and Space Law
}

\author{
King James Nkum ${ }^{*}(\mathrm{PhD}, \mathrm{BL})$ \\ Beida Onivehu Julius** (PhD Candidate, BL)
}

DOI: $10.21827 / 5 \mathrm{~d} 5141 \mathrm{c} 7 \mathrm{c} 5 \mathrm{cb} 9$

\section{Keywords}

INTERNATIONAL LAW; SPACE TOURISM; COMMERCIALIZATION

\begin{abstract}
Space exploration activities constitute an important part of International Air and Space Law. Space Law, which governs matters in outer space beyond the Earth's atmosphere, is a rather new area of law and is to a very large extent connected to Air Law. Not only have we witnessed a tremendous increase in air travel recently, human activities in space has also skyrocketed. Sub-orbital flight and colonization (also known as space tourism) is one of such developments in space activities today and is not without legal implications. This article seeks to x-ray and situates some of these legal issues emerging out of contemporary space exploration activities against the overarching framework of the UN Space Treaties.
\end{abstract}

\section{Introduction}

The commercialization of space due to the latest multifarious commercial space activities has come with emerging legal issues. Commercial air transport has evolved from an elitist means of travel to a commodity for all and sundry for the past 60 years since the advent into that realm. Sub-orbit flight on the other hand has been there since the last 50 years, although commercial human spaceflight is only emerging as a viable industry in most recent times. The first spaceflight carrying humans was undertaken by the USSR on 12 April 1961 wherein Yuri Gagarin travelled in the Vostok-1 mission. ${ }^{1}$ Consequently, space law is maturing by the day, but of course, not without some emerging legal issues being thrown to the front burner. ${ }^{2}$

The last few decades have witnessed diverse forms of tourism, such as Adventure tourism, Agritourism, Ecotourism, Cultural tourism, Heritage tourism, Health tourism, Sport tourism, Disaster tourism, Medical tourism, virtual tourism and latest is space tourism. Just like it was the case with air travel, space tourism is evolving from being considered science

\footnotetext{
* Legal Research Consultant/Staff Legal Adviser Triune Biblical University, USA. kingjamesnkum@gmail.com +2348065319125

** Law Lecturer, Bingham University, Karu, Nassarawa State - Nigeria.

1 See Eilene Galloway 'The History and Development of Space Law: International Law and United States Law' (1982) 7 Annals Air \& Space Law 1, 295, 300; Associated Press, "Private Spaceship Makes First Flight". The Times of India, Kolkata, 12 October 2010; Roger D Launius and Dennis R Jenkins, 'Is it Finally Time for Space Tourism?' (2006) Astropolitics: INT'L J. SPACE POWER \& POL'Y, 253, 255. 
fiction to becoming recognized as an important new target for the space industry. Space tourism has become the vogue where wealthy individuals or corporations are given the rare opportunity to travel beyond the Earth's atmosphere and experience orbital flights. ${ }^{3}$ Part of the main attractions of space tourism is the uniqueness of the experience, the amazing and thrilling feelings of looking at Earth from space, status symbol, and various advantages of weightlessness - potential for extreme sports and health benefits, particularly for the elderly. ${ }^{4}$ This connotes that beside scientific value of space, space tourism is the new venture and reasonable space access is fundamental for the development of this new space business. ${ }^{5}$ Thus, space tourism is the new frontier in travel as man having conquered the earth, is now poised to colonize the universe.

Commercial orbital flight or space tourism is increasing in scope, requiring governmental organizations to play a vital role in exploring this untouched avenue. Part of this intervention would be to look into the exorbitance of orbital flight. It is incredulous that despite having used some billions to develop space technology, government space agencies have not reduced the cost of space travel from what it was when Yuri Gagarin first flew to orbit in $1961^{6}$. Several benefits have been put forward as reasons to encourage space tourism. From an economic point of view, the escalation of sub-orbital tourism has the potential to bring about the development of a large space tourism industry with increased prospects for orbital tourism services, which will be very beneficial both for the space industry, in addition to creating employment opportunities.

In the words of Adhikari, space tourism is an excellent starting point for other private space endeavors because according to him,

"... It has the potential to bring in investors and enthusiasts, create immediate profit, and lay the groundwork for greater research and funding in other space applications. There can be no doubt that the prospect of commercial space tourism flights has captured widespread imagination. The public perception of commercial space travel has changed from mere fantasy to a possibility and will soon be a reality"7

3 Dennis Tito spent $\$ 20$ million on space tourism to become the first paying tourist in 2001 Tito the founder of Wilshire Associates and former JPL scientist traveled aboard Russian Soyuz capsule launched by Space Adventures Ltd. U. S. company where he spent 7 days aboard the International Space Station. See Atrey, Priti. Space Tourism - Future Industry". Current Developments in Air and Space Law. Priti Atrey, 'Space Tourism-Future Industry' (2012) NLUDRS 419.

4 ibid.

5 ibid.

6 In any event, private activities aimed at realizing space tourism have recently demonstrated the prospect of achieving sub-orbital space flights at less than $1 \%$ the cost of comparable flights performed by NASA in 1961. Aditya Jain and Others, 'Current Development in Space Tourism: Space Tourism - A Tool to Break the Existing Shackles'; The X Prize, a new technology breakthrough in commercial travel started in 2004 with Prize for $\$ 10$ million for a Non-Government Organization to launch a reusable manned spacecraft into space twice within two weeks to be conducted as a sub-orbital flight carrying up to three passengers. This prize was won by Burt Rutan on 4th October 2004 in a special vehicle called Spaceship One attached and carried by an aircraft called White Knight. It may be recalled that a similar prize instituted by one Raymond Orteig for crossing the Atlantic from New York to Paris and went to Charles Lindberg for nonstop crossing of Atlantic on 20-21st May 1927.See Prof Ranbir Singh, Prof Sanat Kaul and Prof Srikrishna Deva Rao (ed), Current Developments in Air and Space Law (NLUD Press 2012)

$7 \quad$ Singh (n 6); Malay Adhikari, 'Space Tourism- Legal Issues and Challenges with Special Reference to Current Developments in Air and Space Law. India'(2012) NLUDRS 385. 
The fact that every benefit comes with responsibilities is the reason why this segment sets out to discuss space tourism in detail, bring out the pith and substance thereof with special emphasis on the legal aspect of the venture.

In sum, human spaceflight is emerging as a viable industry due to the commercialization leading to new services, markets, routes, missions, and possibly lower prices. States would have to respond by regulating commerce, travel, and military and diplomatic national interests in space. Collectively, this will increase the importance of international and multilateral cooperation between governments, and underline globalization and international strategic business planning for commercial space companies. ${ }^{8}$

\section{Meaning and Dimensions of Space Tourism}

The World Trade Organization (WTO) and the United Nations Special Statistical Committee (1994) defined space tourism as 'the activities of persons travelling to and staying in places outside their usual environment for not more than one consecutive year for leisure. ${ }^{9}$ Thus, any commercial activity offering customers direct or indirect experience with orbital travel would constitute space tourism. ${ }^{10}$

The tourism aspect of commercial space experience as herein defined becomes realistic when the following distinct elements are available: ${ }^{11}$

(i) A discretionary income available for leisure travel;

(ii) Ample leisure time to spend on both preparations for and taking the trips themselves; and

(iii) An infrastructure supporting tourism that offers accommodations, food and amenities, transportation systems, and attractions to see and do at the place visited.

Robert Goehlich, A Representative Program Model for Developing Space Tourism (2003) 14; Diana Howard (ed), Space Tourism in India: A Collaborative Project off Institute of Air and Space Law; David Ashford, "New Commercial Opportunities in Space"(2007) The Aeronautical Journal<http://www.spacefuture.com/archive/new_opportunities_in_commercial_space.shtml>acce ssed May 12 2019; Ivan Bekey, "Economically Viable Public Space Travel"(1998) Space Future Journal< http://www.spacefuture.com/archive/economically_viable_public_space_travel.shtml>accessed May 12 2019; Proceedings of 49th IAF Congress, 1998; Collins, Patrick. "Space Tourism-the Surprising New Industry". Proceedings of IEEE Aerospace Conference, 1997; Patrick Collins, 'The $\begin{array}{lllll}\text { Space } & \text { Tourism } & \text { Industry } & \text { 2030'(2000) Fuce }\end{array}$ Journal<http://www.spacefuture.com/archive/the_space_tourism_industry_in_2030.shtml >accessed 12 May 2019; Norul Ridzuan Zakaria and Others, "The Symbiotic Relationship between Astronaut Program and Space Tourism Development-A Third World Perspective"(2007)Space Future Journal<http://www.spacefuture.com/archive/the_symbiotic_relationship_between_astronaut_progr am_and_space_tourism_development_a_third_world_perspective.shtml>accessed 12 May 2019; Zahari and Others,"The Symbiotic Relationship between Astronaut Program and Space Tourism Development-A Third World Perspective". Presented at 2nd IAASS Conference, Chicago, 15 May 2007.

$9 \quad$ Adhikari (n 8).

10 ibid: Hobe, Stephen. Et al. "Towards a New Aerospace Convention? Selected Legal Issues of Space Tourism". Proceedings of the Forty-Seventh Colloquium on the Law of Outer Space, 2004, 377.

11 ibid: Frans Von Der Drunk, 'Passing The Buck to Rogers: International Liability Issues In Private Spaceflight'(2007) 86 Nebraska Law Review, 400. 
In addition to the distinct elements considered above as requirements for space travel, different processes are involved in the phenomenon. In view of the fact transportation remains one of the main aspects of space tourism it would mean flight to and from outer space as well as transportation within outer space. As such, there are different approaches of space tourism with different stages and therefore with different legal implications. ${ }^{12}$

In any event, the difference between an aircraft and spacecraft is getting blurred as the concept of sub-orbital flight is becoming a normal part of life - heralding the advent of space commercial travel. A sub-orbital flight is a hybrid which is both an air flight and a space flight. A flight which takes off as an aircraft but switches to rocket propulsion at a certain altitude to go up to about $100 \mathrm{~km}$ vertical and then re-enters atmosphere. ${ }^{13}$ Hence, a sub-orbital flight is like a normal air flight to begin with, but which later goes up practically vertically through air to enter space or micro gravity and then reenters air to save time on intercontinental travel. ${ }^{14}$

In sum, a sub-orbital spaceflight (or sub-orbital flight) is a spaceflight in which the spacecraft reaches space, but its trajectory intersects the atmosphere or surface of the gravitating body from which it was launched, so that it does not complete one orbital revolution. ${ }^{15}$

\section{Stages and Legal Implications of Orbital Flights}

The fact that space is the final frontier to everybody calls for caution in its use particularly when employed for non-scientific ends, such as for tourism purposes. As such, the need to invoke legal aspects regarding space tourism becomes necessary. It is important to state from the onset that the existing legal regimes governing space are insufficient particularly for future space tourism activities, as overstated in this section. In this connection, some of the issues to be considered include: ${ }^{16}$

(i) The issue of authorization and supervision of the space tourists,

(ii) The issue of registering the aircraft/space object carrying the tourist,

(iii) Jurisdiction of the state and control over the same; and

(iv) Passenger liability and more specifically, third party liability. ${ }^{17}$

Highlighted hereunder are the various stages leading to the process of space tourism. There are: ${ }^{18}$

(i) The first stage in sub-orbital flight begins at the surface of the earth - where it also ends. So mainly domestic law rules this part of space tourism. Thus, there are some exemptions by international space law that interfere. ${ }^{19}$

\footnotetext{
$12 \quad$ Adhikari (n 8).

$13 \quad \operatorname{Kaul}(\mathrm{n}$ 6).

14 ibid.

15 Atrey (n 6).

$16 \quad \operatorname{Kaul}(\mathrm{n}$ 6).

17 The most controversial aspect as regards space tourism.

18 ibid.

19 For example, continuous supervision of non-governmental activities in outer space by states, obligation for the launching state to register space objects and to inform the Secretary General of the United Nations etcetera. See ibid.
} 
(ii) Airspace, the second stage, is basically subject to state's territory and sovereignty. In respect of space objects, this rule is limited, and an international passage right is out of question. The rationale for this is the consideration that airspace is just a necessary stage to get into or back from the outer space ${ }^{20}$.

(iii) Orbital residence is the third stage in this regard. The space station ${ }^{21}$ is linked with a hotel-module as one project of space tourism plans. ${ }^{22}$

(iv) Outer Space is the fourth stage in this connection and the legal position is as contained in the OST. Specifically, Article VIII of the treaty ${ }^{23}$ provides to the effect that a state party to the treaty on whose registry an object launched into outer space is carried, shall retain jurisdiction and control over such object, and over any personnel thereof while in outer space or on a celestial body. This provision means that national law, and consequently principles of inherent private international law, is applicable on space objects. ${ }^{24}$

(v) Residence on celestial bodies is the final stage, which is mainly regulated by the Moon Agreement, 1979. Additional provisions can be found in the Outer Space Treaty, but these are rather broad and imprecise. The basic rules of space law, like the freedom principle and the common-heritage-principle, are undoubtedly fully applicable. Added to this are the ecological and ethical dimensions, because permanent bases or colonies on celestial bodies will have to deal with weather-conditions that are rather different from what is obtainable on planet earth. The aspect of terraforming to establish an earth-like atmosphere and environment on a celestial body - is apart from technical difficulties less of a legal problem, but merely an ethical question. ${ }^{25}$

The questions of jurisdiction have to be regarded under the viewpoint of the ISS Agreement ${ }^{26}$ which basically follows the link-up-principle. Liability in respect of the ISS Agreement could be a contractor or subcontractor of a Partner State, a user or customer of a Partner State, and a contractor or subcontractor of a user or customer of a Partner State. The Partner States are enabled to exclude by domestic law the applicability of the Liability Convention ${ }^{27}$ concerning the ISS with effect against third parties.

Whether space is used to greater effect by governments or commercial interests, it is a common domain shared by all who operate in space and it is in the collective interest to

\footnotetext{
20 ibid.

$21 \quad$ International Space Station.

22 See generally<http://www.nasa.gov/mission_pages/station/main/index.html>accessed 11 May 2019.

23 Outer Space Treaty (adopted 5 December 1979, entered into force 11 July 1984) 610 UNTS 205.

$24 \quad$ Adhikari (n 8).

25 ibid.

26 International Government Agreement on the Space Station< https://www.esa.int/Our_Activities/Human_and_Robotic_Exploration/International_Space_Statio n/International_Space_Station_legal_framework>accessed 12 February 2015.

27 United Nations General Assembly, United Nations Treaties and Principles on Outer Space (United Nations Publications 2002).
} 
preserve the space environment both now and in the future. ${ }^{28}$ The ISS is a major international endeavor and success. With the participation of five countries this nearly 10 -year-old platform in space about $460 \mathrm{~km}$ in low earth orbit has added a new dimension to space flights. The ISS programme also achieved a major success bringing about a commonality of documentation between the Kennedy Space Centre in the US, The Guiana Space Centre in French Guiana and the Tanegashima Space Centre (TNSC) of Japan. This is certainly a milestone international achievement in space cooperation. ${ }^{29}$

At the crux of the matter is the need for a comprehensive as well as exhaustive space legal framework to regulate space tourism. Moreover, with many private entities delving into space adventure in a competing effort, it therefore means that space activity is currently at a crucial juncture where rules and regulations are required to control such flights because as more countries join in there can be a chaotic growth of suborbital traffic. ${ }^{30}$ The position today is that the US Federal Aviation Authority (FAA) is involved in the global effort of preparing rules and regulations for this new endeavor driven by the private sector. The US Commercial Space Launch Act (CSLAA) was enacted in 2004 which entrusts Department of Transportation with the task of making regulation and FAA the responsibility of regulating for safety crew and space flight participants. Accordingly, FAA has issued Guidelines in 2005 for Commercial Sub-orbital Reusable Launch Vehicle Operations with space flight participants. ${ }^{31}$ Other countries like UK have also enacted UK Outer Space Act which authorizes the Secretary of State to give a license for space activities. Similarly, other States like Russia, Ukraine have their own laws. More and more countries are coming up with their laws concerning commercial space flights but are not harmonized with each other. ${ }^{32}$

This initiative is a step in the right direction, although these legislations do not have international consensus or binding force. As long as these sub-orbital flights remain within the 'domestic' realm, (leaving a country and returning to the same country and not entering anyone other country's airspace), there is no legal issue. Provided these flights remain' domestic' there may not be an issue, but the moment they become international, many issues will come into play. ${ }^{33}$ Howbeit, once a sub-orbital flight leaves one country and lands in another, it amounts to an international flight and many issues of international law come into play. We now also face the issues of launch vehicles having multiple owners/operators. For instance, Virgin Galactic is a US based company with its parent company in UK planning a fleet of five sub-orbital vehicles to carry six paying passengers per vehicle who may be of any nationality but will probably operate from US. The first space Tourist Dennis Tito was a US national, but he took a commercial space flight from a Russian Government owned Soyuz spacecraft from Kazakhstan in 2001 which docked with the ISS. In case of a mishap there would be legal issues of compensation.

The fact that successful orbital flights have taken place with announcement by other companies means that travel through sub-orbital trajectory is no more a futuristic dream but

$\begin{array}{ll}28 & \text { Kaul (n 6). } \\ 29 & \text { ibid. } \\ 30 & \text { ibid. } \\ 31 & \text { ibid. } \\ 32 & \text { ibid. } \\ 33 & \text { ibid. }\end{array}$


an immediate possibility. In view of this development, the questions that come to mind include: ${ }^{34}$

(i) How these flights are to be treated,

(ii) Whether they come under air and therefore under the Chicago Convention of 1944 ,

(iii) Whether the space are flights,

(iv) Whether rules should not be made for them as done civil air flights,

(v) How the legal issues of compensation will be determined in the case of a mishap.

The above questions bring to the fore the need to review the present legal status of suborbital flights. The Council of ICAO has a clear mandate to adopt Standards and Recommended Practices for civil international aviation under Article 37 of the Chicago Convention $^{35}$. The ICAO system is yielding positive results as air travel has become the safest mode of transportation. However, for Outer Space flights there are a separate set of Conventions under international law. As a result, the need to provide flight path and monitor the progress of a sub-orbital flight becomes even more essential as issues relating to re-entry are another set of technical requirements. As such, certain issues need to be looked into, which include safety, sovereignty, security, environmental, liability ${ }^{36}$ as well as the provision of an institutional framework. ${ }^{37}$

In any event, while convergence is taking place between air and space in connection with the coming of commercial sub-orbital flights, there is no overemphasizing the fact that the legal regime governing the two also requires convergence, harmonization and a filling up of the vacuum in the laws governing the two sectors. COPOUS ${ }^{38}$ has been working on two

ibid.

35 It has achieved this by providing Air laws in the form of 'Standards and Recommended Practice'. All members' countries of ICAO have to follow it and ICAO conducts audit to check the implementation by each country terms of safety and security. There are 18 Annexes to the Chicago Convention laying down there SARPs in different categories. Ibid.

A huge investment as space travel will require a liability regime. The existing Montreal Convention 1999 (Successor to the Warsaw system) on legal liability extends only to air flights and there would be difficulties in case an accident takes place in space. The Liability convention for space provides damages under article II. It states that a launching state shall be absolutely responsible to pay compensation for damages caused by its space object on the surface of Earth or to an Aircraft in flight" While no vertical limit of air has been specified it does not specify the damage caused by space debris but only damage caused by the space object in air and on ground. It is therefore interesting to note that neither Montreal Convention 1999 nor the Liability Convention can mitigate the issue of a sub-orbital flight getting hit by space debris. The issue of launching state is another interesting feature. Today there are only a handful of launching states while procuring states, that is state of manufacture, are many more. As a result, the responsibility of a launching state becomes very high especially as more and more nano satellites will be put into orbit. Kaul (n 6).

36

ibid.

Such an agency or institution is required to provide Air Traffic Management (ATM) as well as Communication, Navigation and Surveillance (CNS) functions while the object is in space and at the point of re-entry.

UNCOPOUS is a committee of UN and is not empowered to make rules and regulations the way the Council of ICAO is. It is the institutional structure of COPOUS which inhibits it from making international law. The Council of ICAO, on the other hand, is empowered to do so. 
major issues of space namely, use of Nuclear Power Sources in outer Space and developing standards for space debris mitigation..$^{39}$ Unfortunately, the achievements of COPUOS have been limited and while it has established good working relations with space faring nations, its scope and membership is limited. Another organization which is closely associated with aviation and space activities is the ITU. It has the most important function of allocating radio frequencies and spectrum to all countries which have now become a scarce commodity; it not only allots a bandwidth to a country, but it also allocates the parking slot to each satellite. ${ }^{40}$ The ITU therefore, has a crucial role to play in aviation and in the space industry. These institutional efforts should be fused into one towards an effective space-faring experience. Consequently, there is need for additional amendment to the Chicago Convention to make standards and recommended practices for sub-orbital flights.

\section{Requirements for Space Tourism Activities}

A qualified space system requires certain essential features to be in place for successful space tourism activity and infrastructure. The most important requirements a space tourism system have to meet are summarized by Adhikari as follows: ${ }^{41}$

(i) The space tourism system has to come up to expectations of space tour participants, namely to the most preferred ones: looking at earth and experience of weightlessness. The vehicle design should therefore provide a sufficient number of windows and sufficient interior space to fly around.

(ii) High inclined orbits are favorable, covering a greater proportion of earth's surface.

(iii) Due to medical restrictions the acceleration level should be kept lower than 3G.

(iv) Although most survey participants prefer longer space trips, it would be recommended to limit the space tour to several hours in accordance to avoid space sickness. There is no general time limit until space sickness will occur, but it has been shown that in the first hours of space flight the space sickness rate is at low levels.

(v) By reducing flight time, some space tourists may think to get insufficient service for their money. To compensate for this feeling a kind of luxurious space camp should be implemented before each space flight. In providing technical information, health monitoring and professional space training, a space camp will intensify the feeling of becoming a "real astronaut". A great psychological momentum in gaining customer's content.

(vi) In general, appropriate procedures are required to proof health conditions of space tourists. Because of the fact that some tourists will be dismissed from space flight due to medical reasons, it would be recommended to accomplish health inspections very wise, best in connection with a space camp.

(vii) Most important, it would be essential to meet the demand price figures. Considering the market surveys, a sufficient demand will be established at ticket prices of $\$ 50,000$ or less.

$\begin{array}{ll}39 & \text { Kaul (n 6). } \\ 40 & \text { ibid. } \\ 41 & \text { Adhikari (n 8). }\end{array}$


While other issues exist as necessary for a hitch-free sub-orbital experience, the foregoing features are essential and worthy of consideration.

\section{Conclusion}

The exploration of space and its attendant commercialization particularly with reference to orbital flights has become a 21 st century reality due to technological advancement. If properly explored and exploited, this feat could become a lucrative industry, which will definitely lead to the furtherance of space law beyond its current scope. This requires investment into the sector by more states. However, the need to comply with international legal framework on space and orbital activities is crucial to the realization of this feat.

$*$

www.grojil.org 